\title{
Zentralbibliothek Zürich: A new Library - Ten Years after
}

\author{
by HERMANN KÖSTLER
}

\section{Translation: Anne Marie Wells}

\section{HISTORY, FROM 1629 TO 1995}

On the sixth of February 1629, four young citizens of Zurich founded a library that was open to the public: the Stadtbibliothek, or 'city library'. Because the library grew so quickly, the city council relocated it to the Wasserkirche, a church dating from the late Middle Ages that had been deconsecrated after the Reformation, and which is situated on an island in the river Limmat. From 1634 to 1917, that library served the dual goals of education and scholarship.

How far back one might trace the construction history of the Zentralbibliothek at today's location on the Zähringerplatz will probably never be determined precisely. What we do know fairly well is the history of the past 800 years. At the beginning of the thirteenth century, Dominican monks, the preachers (the 'Prediger'), settled on this site. In about 1230, the Predigerkirche was built as part of the Dominican monastery, probably on the site of an earlier church. The buildings of the monastery served as a hospital in the nineteenth century, and burned down in 1887. Thus came into being the so-called Amtshausplatz, the only open space in the centre of Zürich that was suitable for a large new building.

Here the Zentralbibliothek opened its new building in 1917. It was created through the merger of the city library that had begun in 1629, the cantonal library founded in 1835, and the three specialized research libraries of the scientific, legal, and medical societies. The canton and city signed a contract in 1910 that established the Zentralbibliothek Zürich as a foundation. This contract was reconfirmed and approved by the electorate of both canton and city in 1986 .

The Zentralbibliothek Zürich is a public provider of staple information. To fulfil this elementary requirement, Zürich's citizens have in the twentieth century twice shown their dedication to their large library, by authorizing major building projects. This first happened in 1914, when the term "Information Management" had not yet been created, and a second time in 1986, when the term was on everybody's lips.

In 1914, the voters in the canton and city approved the necessary funds for the construction of the first library building. This was conceived to be functionally excellent in its day. The use of books and periodicals was made as easy and handy for the public as conventional methods at that time would allow: card catalogues listed the library holdings, and the staff delivered the books from the closed stacks to the reading room or to the circulation desk.

The success of this library service organization led to insufficient space for public, staff, and books by the end of the 1930s. At first hesitantly, then more energetically, and finally in near desperation, emergency measures had to be taken because the ever-pressing, essential library extension did not come about: a building programme, an architectural competition, planning, budgeting, parliamentary debate by the canton and city councils - each step demanded a great deal of time altogether, during which the number of library users grew to more than 50,000, new acquisitions required an additional kilometre of shelf space per year, and the annual book circulation rose into the hundreds of thousands. After waiting for several decades, the Zentralbibliothek was able to begin its expansion in 1990. Many in Zurich will remember the spectacular explosive demolition of the houses in the Chorgasse that marked the start of construction work.

The experience of moving out in 1990 fundamentally influenced our return into the new extension in 1994 . We moved into a new - for users and staff - functionally structured building, which is the subject proper of my talk today. As much as possible was built on the relatively small area that belongs to the Zentralbibliothek Zürich Foundation. With sufficient space still remaining in the stacks, we will not have to worry on behalf of our public for several decades to come.

\section{PLANNING}

Looking back, we have to say that the planning in all its phases took decades to complete. Building programmes, 
project drafts, preliminary plans, and even the possibility of moving the library to another location were all considered in the years after 1947. At one point, the building committee disbanded after the canton and city adopted a general moratorium on new construction work. An unbroken development from 1971 onwards led to the inauguration of building work in 1990: the building programme, the assembling of an array of experts' reports on it, the architectural competition, the project financing, the revision of the building plans, commissions, detailed design with cost estimates, opposition from residents and the committees responsible for maintaining historical monuments, a replanning of the administration section, approval by the board, parliamentary commissions, a publicity campaign before the public vote, satisfying challenges to the building permit - all this took two decades. If the saying is true that good things take time, then we must surely - considering the time we took - have now acquired the best library in the world.

Representatives of the library staff were kept continually informed as to the builders' detailed plans. Twice during the many years of work, we presented the plans to the entire library staff for their critical appraisal. This aroused a profusion of suggestions - some of which brought real improvements to the project - and even more requests, some of which could be fulfilled.

One example may stand for many to show how good ideas from the staff contributed to the planning: with some difficulty we convinced the builders to provide from the onset all five floors of stacks with rails for rolling bookcases, even though the original arrangement had called for fixed cases. Those fixed stands that we wanted to be moveable later on were immediately placed on trolleys and blocked. This made change easy: in the years 2002 and 2003 we could simply attach cranks to the bookcase rows and have the blocks removed. The big job - removing and re-shelving the books - was thereby avoided.

The subject of fire safety presents a further example of a successful change of plan. Experts persuaded us that the most effective protection above ground was a sprinkler system. Underground, that is, in the stacks, the control panel turns off all power to lights, machines, and outlets at closing time. The planned firewalls were installed in the stacks, but thanks to the sprinkler system we could do without them from the ground level to the third floor. The public rooms consequently gained considerably in spaciousness and visibility.

A far-reaching change challenged the creativity of the librarians: as a reward for vacating the building area completely and not moving into parts of the new building immediately, as had originally been planned, we were offered a construction period of 5 instead of 8 years. If not before, then certainly in this phase, the librarians could demonstrate and bring into play everything that they had never been taught during their training: imagination, creativity, logistics, improvisation; to find, plan and direct temporary solutions, to haggle with workmen, to negotiate with authorities, to make the impossible possible on a daily basis. After years and decades of moving at a snail's pace (and not always in a forwards direction), users and staff had suddenly to give up their space and time, impossibly quickly, so that construction could begin.

It was never an option for the Zentralbibliothek, an information-providing enterprise, to halt its services during the construction period. For the mass lending operation from the open and closed stacks we consequently looked for a large factory hall and found two arsenals on the grounds of the former army barracks; the library of the Federal Technical University (ETH) made one of their modern stacks on their Hönggerberg campus available for our old book collection. And additional four off-site storehouses took the rest of the library's holdings. We made it a point of honour that everything would remain accessible to the public, even if a slower service for the users and greater efforts from the staff were the price to be paid. A book van circulated between the branches of the so-called "Dezentralbibliothek", or "Decentral Library"; for this period, some scholars preferred to retreat into the libraries of their university institutes.

In 5 years we had to bother our public twice, closing each time for several months - terrible, library-free times - in order to move our collection. Inevitable and uncomprehending protests remained within the realm of what one would expect. On the whole, our efforts to maintain our service as the information provider to the canton, city, and university earned appreciative tributes.

\section{THE PRESENT}

Operational needs determined construction not only in 1917 but also in 1994. Above all, the division between public and staff areas had already proven to be sensible in the first building, but could not be maintained due to the rapid growth of the administration. The extension re-established this sensible division: the administrative departments are housed in the new administration wing and have direct access to the public wing except on the ground level. Areas with delivery and dispatching operations are located near the garage and service lift; a book-transport system connects 
the old building, the public wing, and the administrative wing on all levels.

Leaving aside the Predigerchor, which houses the music library, there is only one entrance for the public: the door onto the Zähringerplatz from the old building of 1917. The parking spaces for handicapped users, accessible from the Mühlegasse, are an exception.

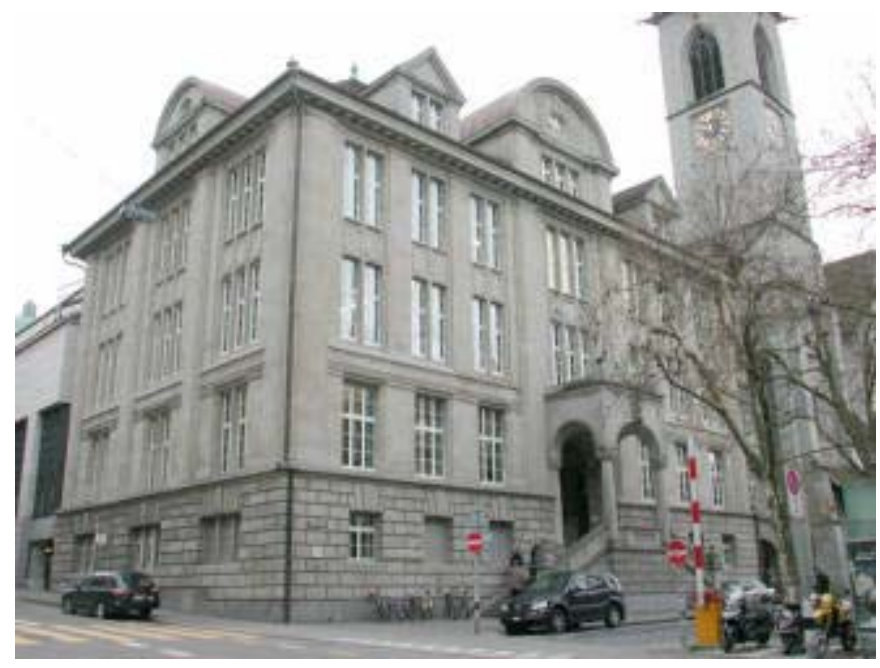

In the old building, the vestibule (Level 0) serves as a traffic roundabout for visitors. Above it, on Levels 1 to 3, are the special collections for rare books, manuscripts, prints and drawings, and maps; the staircase down to Level 01 leads into the extension where there are seminar rooms, a lecture hall, and the cafeteria. From the vestibule one may reach the circulation desk without having to deposit briefcase and bags in the cloakroom. Two computer screens for catalogue inquiries and book requests are also located in this area.

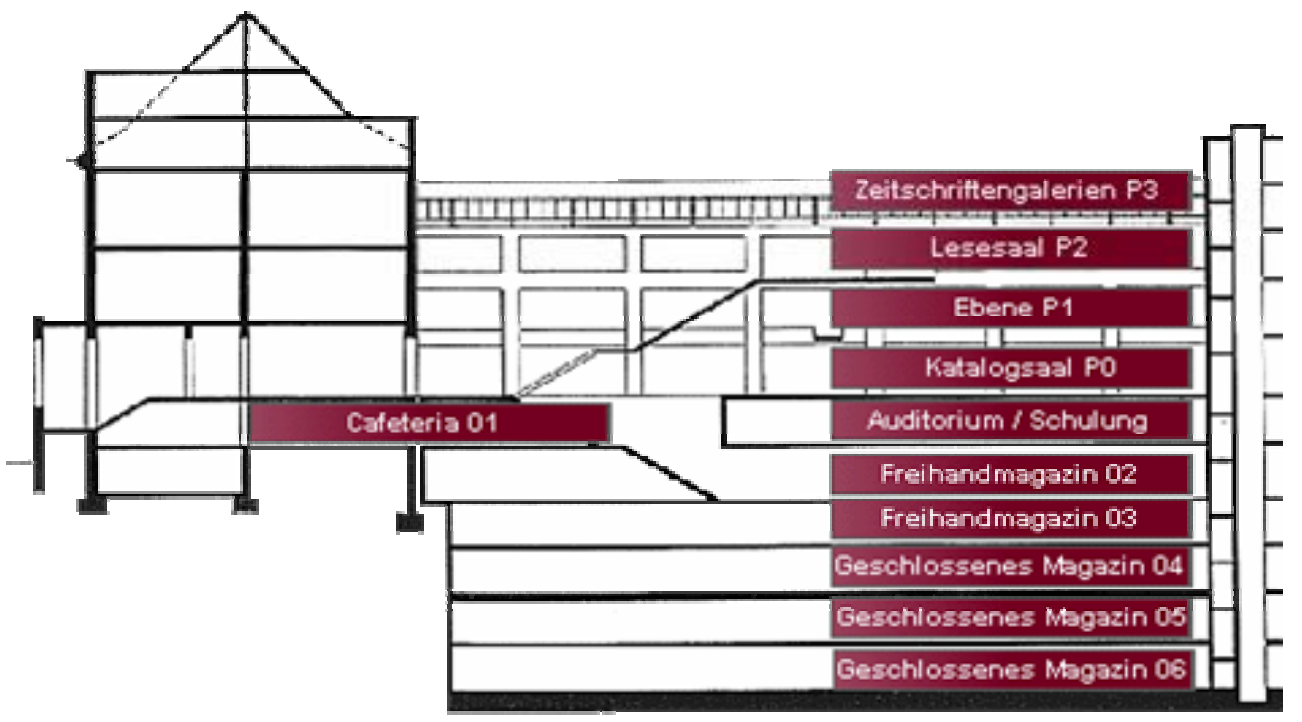

Walking straight through the vestibule takes us into the new public wing. Here, we find the catalogue hall, and a large staircase before us. Going up the stairs leads to the entrance to the reading rooms on Level 2, going down the stairs takes us to the upper level (Level 02) of the two open-stack floors. It was arranged that the reference collection would be upstairs, and the open access collection below.

Besides conventional and electronic catalogues, the catalogue hall contains the information desk, general bibliographies, and workstations for database inquiries and internet use. When coming out of the open stacks, users can 
have books checked out before leaving the hall.

A wide staircase and two lifts ascend to Level 2 and the entrance to the reading rooms. The reading rooms are furnished with worktables, reference works along the walls, stations for laptop connections, and offer a separate room with photocopiers and reader-printers.

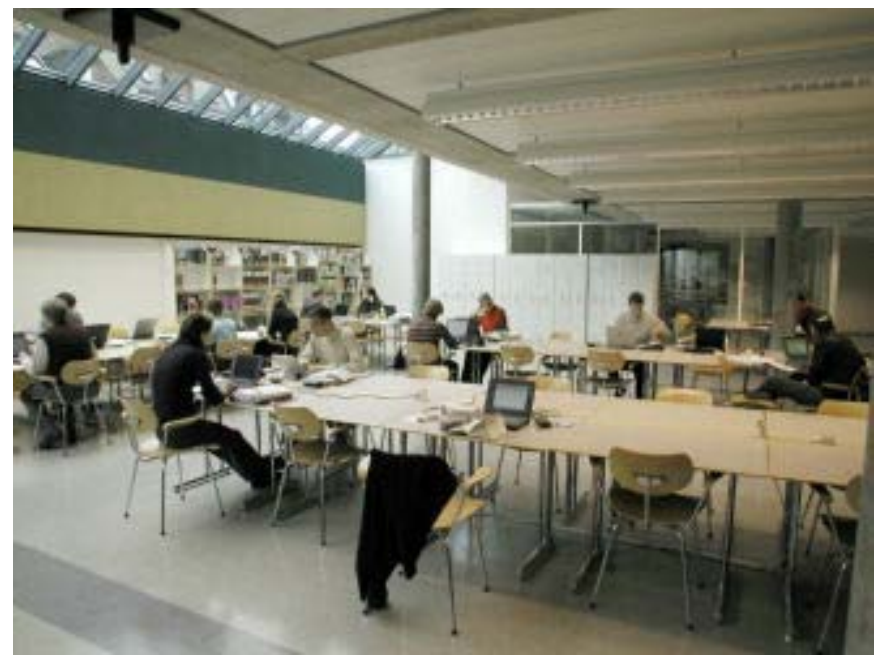

In front of this room stands an apothecary cabinet holding the most frequently requested microfilms. Below, on Level 1 , is the systematically arranged, main body of the reading room collection. Above, in two galleries on Level 3, are the unbound periodicals from the current year. The public may use the lift behind the reading room desk, which is usually reserved for staff, to go down to the earlier, bound periodicals in the stacks (Level 04).

In this regard one mistake on our part should be recorded: we thought it would be a good idea not to store the newest bound periodicals in the basement stacks straight away, but rather to place them first on the floor above the periodical galleries in the same order as the unbound issues below. After a few years we realized that the public was ignoring this convenience, so we stopped making an administrative effort for a service that was unappreciated. Today, bound volumes are shelved immediately in the Level 04 stacks, which users can reach from the reading room.

Beneath this Level 04, we have the sheltered stack areas 05 and 06, with 06 containing a vault for the library's most valuable possessions. Steps and two lifts descend to the open stacks 02 , only the two lifts to 03 . The concept for these levels was the result of a compromise between comfort and maximum availability. A lot of possible shelf space is lost to stairwells, lifts, book-transport systems, and ventilation ducts. Nowhere did we give in to using the conventional norms for dimensions in the open stacks, but rather we reduced the shelf depth to between 18 and $21 \mathrm{~cm}$ and provided a space of only $3 \mathrm{~cm}$ between the shelves, thus creating a passage 80 to $90 \mathrm{~cm}$ wide from an average interaxis of 135 $\mathrm{cm}$. For the rolling bookcases in the open stacks the public is often satisfied with a passage 70 , or even 60 , $\mathrm{cm}$ wide. Several years of experience have shown that the circulation of users on the two levels of open stacks functions without a problem.

\section{THE OPEN STACKS AT THE ZENTRALBIBLIOTHEK ZÜRICH}

Something has to be said on the subject of open stacks, because in this area the Zentralbibliothek Zürich differs a little from what is usually understood by the term. As it turned out to be impossible to manage the drastically rising circulation figures with our existing staff, we were already compelled to adopt open stacks in the old building. All the shelf marks in the closed stacks were so well arranged that we had practically only to unlock a few doors to make open stacks available to the public.

The system of shelf marks that the Zentralbibliothek introduced soon after its founding is made up of three elements: two capital letters and a running number. 
The first capital letter denotes a time period:

$\mathbf{A}=$ works up until 1880

$\mathbf{B}=1881$ to 1915

C $=1916$ to 1950

$\mathbf{F}=1951$ to 1982

$\mathbf{G}=$ since 1983 .

Several first capital letters specify the publication type:

$\mathbf{D}=$ pamphlets and brochures

$\mathbf{T}=$ series

$\mathbf{U}, \mathbf{X}, \mathbf{Y}=$ periodicals.

The second capital letter indicates a subject:

$\mathbf{A}=$ general (Allgemeines) to $\mathbf{V}=$ Various (Varia).

Domains of various book sizes are designated by running numbers:

- $\quad$ Books up to $33 \mathrm{~cm}$ high $=100$ to $199 ; 1,000$ to 1,$999 ; 10,000$ to 19,999

- $\quad$ Books up to $27 \mathrm{~cm}$ high = 200 to 299; 2,000 to 2,999; 20,000 to 29,999

- $\quad$ Books up to $24.5 \mathrm{~cm}$ high = 300 to 599; 3,000 to 5,999; 30,000 to 59,999

- $\quad$ Books up to $21.5 \mathrm{~cm}$ high $=600$ to $999 ; 6,000$ to 9,999; 60,000 to 99,999.

Thus, the shelf mark FN 259 identifies a work that was published between 1951 and 1982, has history as its subject matter, and is somewhere between 24.5 and $27 \mathrm{~cm}$ in height.

From the start, we disregarded the rule of systematic arrangement and offered instead the open stacks collection arranged in very rough subject groups. We sinned against the standards of minimum distances between bookcases; we did not concern ourselves with the dogma that rolling bookcases overburden the public.

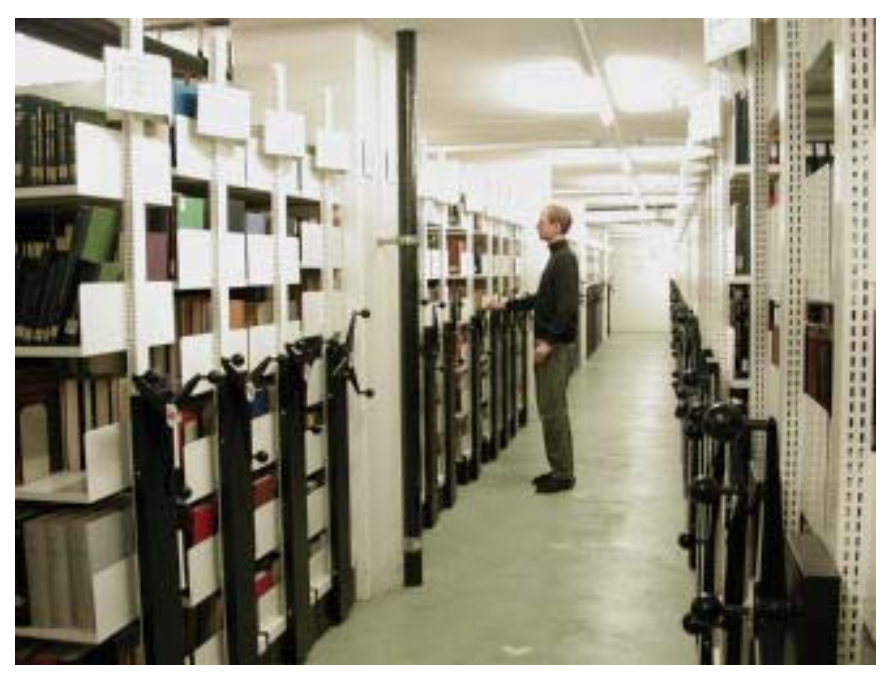

Success proved us right: the public's clear assent, an unchanging yearly loss rate of less than 0.5 per cent, and no disorder in the stacks have been our experience. At present we offer 1.2 million volumes in the open stacks, about a third of our total collection. By fully equipping the open stacks with rolling bookcases - mechanical and not electric, of course - we can raise this number to 2 million. Four-fifths of book loans are made by the public themselves from the open stacks, with only a fifth having to be delivered from the closed stacks. 


\section{TEN YEARS LATER}

In 1994 we opened our large extension, and in 1995 all renovation in the old building and the Predigerchor was completed. Ten years of living in and with the building complex $\mathbf{A}-\mathbf{P}-\mathbf{V}-\mathbf{C}$ (Altbau: old building, Publikumstrakt: public wing, Verwaltungstrakt: administration wing, Chor: choir) allow us to confirm that the construction was very successful and that we would plan little differently. An unusually long planning period, during which many ideas were developed, tested, pursued or rejected, was certainly a help. Only in a few places in the project would we make changes. Until now, we have also been able to accommodate new developments in the building, such as access to electronic publications and the internet. The flexibility that everyone talks about, and which is habitually demanded of new buildings, in fact occurs mostly in one's mind, and less in the buildings themselves. What had to be put to a different use than had been expected was not rebuilt; instead we took the building as it is and adjusted ourselves to new uses - and not unsuccessfully.

Another subject, to be sure, is the quality of the workmanship of the building. Repeated water damage, a control system for the electronic equipment unsuitable for the year 2000, machine units that hardly did their job, bookcases of the worst quality in the stacks - this list could be easily expanded. The common denominator in all this is cheap, cheap, cheap. The building credit approved by popular vote was cut by $10 \%$ for political show. For us, that meant nine million francs withheld. Without doubt, correcting the many defects that resulted was far costlier than it would have been to buy better quality during the construction period. Were we to build again, then we would want an independent construction expert in attendance during the building work, on a full salary, constantly present on a daily basis, in the construction office and on the site, to protect the interests of the owner.

\section{WEB SITES REFERRED TO IN THE TEXT}

Zentralbibliothek Zürich. http://www-zb.unizh.ch/ 